\title{
STUDENT SUPPORT PROGRAM TO REDUCE STRESS, ANXIETY, AND DEPRESSION ON MEDICAL STUDENTS
}

\author{
Nurfitri Bustamam ${ }^{1 *}$, Ria Maria Theresa ${ }^{1}$, Sri Wahyuningsih ${ }^{1}$ \\ ${ }^{1}$ Faculty of Medicine, Universitas Pembangunan Nasional Veteran Jakarta, Jakarta - INDONESIA
}

Submitted: 07 November 2019; Final Revision from Author: 27 May 2020; Accepted: 23 June 2020

\begin{abstract}
Background: Medical education is considered as being stressful which may cause stress, anxiety, and depression. The student support program is designed to help students of the Faculty of Medicine Universitas Pembangunan Nasional Veteran Jakarta (FMUPNVJ) build resilience to the stress through education and coping skills training. This study aimed to evaluate this supportive program on stress, anxiety, and depression levels, as well as academic performance.

Methods: This study used a one-group pretest-posttest design. Thirty of third-semester students who were randomly chosen and had psychological problems according to the criteria were offered to join the program. The program used problemfocused coping and emotion-focused coping methods in eight sessions for four weeks. Before and after the program, students were evaluated using the Depression Anxiety Stress Scale-42 questionnaire and their academic performance based on block exam results.

Results: Wilcoxon test showed a decrease in levels of anxiety $(p=0.003)$ and depression $(p=0.004)$ after the program. There was no difference in stress levels before and after the program $(p=0.073)$, but there were a tendency stress levels of the subject to be lower after the program. Wilcoxon test showed an increase in the practice exam result $(p=0.000)$. There was no difference in theory exam results before and after the program ( $p=0.358)$, but there was a tendency that the exam result to be higher after the program.

Conclusion: The student support program has an indication for overcoming psychological problems and improving the academic performance of FMUPNVJ students.
\end{abstract}

Keywords: academic performance, medical students, psychological problems, student support program

\section{ABSTRAK}

Latar belakang: Pendidikan dokter adalah pendidikan yang penuh dengan tekanan yang dapat menimbulkan stres, kecemasan, dan depresi. Program dukungan mahasiswa (PDM) dirancang untuk membantu mahasiswa Fakultas Kedokteran Universitas Pembangunan Nasional Veteran Jakarta (FKUPNVJ) membangun ketahanan terhadap stresor melalui edukasi dan pelatihan coping skills. Penelitian ini bertujuan untuk mengevaluasi pengaruh program dukungan tersebut terhadap tingkat stres, kecemasan, dan depresi, serta performa akademik.

Metode: Penelitian ini menggunakan one-group pretest-posttest design. Tiga puluh mahasiswa semester tiga yang dipilih secara acak dan mempunyai masalah psikologis sesuai kriteria ditawarkan untuk mengikuti PDM. Metode yang dipakai selama delapan kali pertemuan dalam waktu empat minggu adalah problem-focused coping dan emotion-focused coping. Sebelum dan sesudah PDM, mahasiswa dievaluasi dengan kuesioner Depression Anxiety Stress Scale-42 dan performa akademiknya berdasarkan hasil ujian blok.

*corresponding author, contact: nurfitri.bustamam@upnvj.ac.id 
Hasil: Uji Wilcoxon menunjukkan ada penurunan tingkat kecemasan $(p=0,003)$ dan depresi $(p=0,004)$ setelah mengikuti PDM. Tingkat stres mahasiswa setelah mengikuti PDM tidak berbeda dibandingkan dengan tingkat stres sebelum mengikuti PDM $(p=0,073)$, tetapi ada kecenderungan tingkat stres subjek lebih rendah setelah mengikuti PDM. Uji Wilcoxon menunjukkan ada peningkatan hasil ujian praktikum ( $\mathrm{p}$ $=0,000)$. Tidak terdapat perbedaan hasil ujian teori sebelum dan setelah mengikuti PDM $(p=0,358)$, tetapi ada kecenderungan hasil ujian teori lebih tinggi setelah mengikuti PDM.

Kesimpulan: PDM mempunyai indikasi untuk mengatasi masalah psikologis dan meningkatkan performa akademik mahasiswa FKUPNVJ.

Kata kunci: mahasiswa kedokteran, masalah psikologis, performa akademik, program dukungan mahasiswa

\section{PRACTICE POINTS}

- Berbagai stresor yang dihadapi mahasiswa dalam pendidikan dokter dapat menimbulkan masalah psikologis dan menurunkan performa akademik.

- Mahasiswa kedokteran perlu dibekali agar mempunyai ketahanan terhadap stresor.

- Program dukungan mahasiswa dalam bentuk edukasi dan pelatihan coping skills dapat membantu mahasiswa kedokteran membangun ketahanan terhadap stresor.

\section{PENDAHULUAN}

Hasil penelitian menunjukkan bahwa pendidikan dokter bukanlah lingkungan yang optimal bagi kesehatan psikologis mahasiswa. ${ }^{1-3}$ Sejak tahun pertama mahasiswa kedokteran sudah menghadapi berbagai tekanan, antara lain jauh dari keluarga, harus beradaptasi dengan lingkungan belajar yang baru, materi pembelajaran yang luas dan beragam, melakukan diseksi cadaver, dan ujian. Interaksi interpersonal antara mahasiswa dan dosen dapat pula menjadi tekanan bagi mahasiswa. Tekanan lainnya dalam pendidikan dokter adalah menyaksikan pasien yang sekarat atau kematian, permasalahan pribadi berupa cedera atau sakit, dan perubahan status kesehatan atau kematian anggota keluarga. Hasil penelitian menunjukkan bahwa sumber stres terbesar pada mahasiswa kedokteran berkaitan dengan akademik, khususnya ujian dan content curriculum yang berlebihan. ${ }^{1}$

Paparan reguler terhadap tekanan akademik tersebut menimbulkan perubahan pada rutinitas harian, misalnya kurangnya waktu tidur dan makan yang tidak teratur. Kegagalan untuk mengatasi tekanan tersebut secara efektif menimbulkan distres psikologis dan masalah bagi performa akademik. ${ }^{4}$ Hasil penelitian menunjukkan tingginya prevalensi stres yang sejalan dengan tingginya gejala depresi pada mahasiswa kedokteran. ${ }^{3}$ Data lainnya menunjukkan prevalensi kecemasan berkisar antara 7,7-65,5\%, depresi $6,0-66,5 \%$ dan distres $12,2-96,7 \%$ pada mahasiswa kedokteran di Eropa. ${ }^{5}$ Di Karolinska Institute Medical University, Stockholm didapatkan prevalensi depresi mahasiswa kedokteran 12,9\% lebih tinggi dari prevalensi pada masyarakat umum. ${ }^{6}$ Penelitian di Hongkong menggunakan kuesioner DASS menunjukkan tingkat depresi, kecemasan, dan stres pada mahasiswa kedokteran lebih tinggi daripada mahasiswa fakultas lainnya. ${ }^{7}$ Di FK Universitas Andalas, Indonesia diketahui 35,7\% mahasiswa mengalami distres ${ }^{8}$ dan di FK Lambung Mangkurat, Indonesia didapatkan berturut-turut prevalensi kecemasan mahasiswa semester I dan II sebesar $37,4 \%$ dan $12,5 \%{ }^{9}$

Tingginya masalah psikologis pada mahasiswa kedokteran menimbulkan berbagai masalah lainnya, misalnya penyalahgunaan obat, alkohol, menyalahkan diri sendiri, dan tingginya ide bunuh diri. ${ }^{7,10}$ Dilaporkan pula mahasiswa yang mengalami distres pada awal masa pendidikan dokter akan terus mengalami distres selama pendidikan dokter. Stres juga berkorelasi secara negatif dengan empati. Selanjutnya rendahnya empati menyebabkan ketidak- 
puasan pasien, masalah komunikasi dokter-pasien, dan medical error. ${ }^{10}$ Dengan demikian, masalah psikologis yang dialami mahasiswa kedokteran, tidak saja memengaruhi proses pembelajaran, tetapi juga tugasnya sebagai dokter di masa mendatang. Selanjutnya, kesehatan dokter berdampak terhadap kualitas layanan kesehatan bagi pasien dan komunitas. Dilaporkan adanya kaitan antara distres atau depresi dengan medical errors. ${ }^{7}$

Sesungguhnya berbagai tekanan baik yang berkaitan dengan pengalaman belajar dan hubungan interpersonal di dalam dan di luar kampus yang dihadapi selama pendidikan dokter merupakan tantangan yang dapat mendorong pengembangan diri mahasiswa. Namun, sejumlah mahasiswa menjadi kewalahan (overwhelmed) dengan hal tersebut sehingga membutuhkan dukungan. Dukungan bagi mahasiswa penting untuk memfasilitasi pengembangan personal dan profesional. ${ }^{11}$

Apabila tidak ada dukungan di kampus, mahasiswa akan mencari upaya sendiri untuk mengatasi stres yang mereka alami. Hasil penelitian menunjukkan untuk menghadapi stres, sebagian besar mahasiswa meminta bantuan teman, senior, keluarga, melakukan hobi, atau kembali kepada keyakinan (agama). Hanya sebagian kecil yang meminta bantuan profesional (penasehat akademik, psikolog atau psikiater), bahkan ada yang melakukan koping maladaptif (minum alkohol atau penyalahgunaan obat). Hasil survei menunjukkan $78,8 \%$ mahasiswa kedokteran di Hongkong menginginkan adanya dukungan bagi mahasiswa untuk menghadapi stres. ${ }^{?}$

Di dalam Standar Pendidikan Profesi Dokter Indonesia disebutkan pembimbing akademik (PA) serta unit bimbingan dan konseling harus ada di institusi pendidikan dokter dan diampu oleh dosen yang mendapat pelatihan tertentu untuk membantu mahasiswa mengatasi masalah akademik dan nonakademik. ${ }^{12}$ Fakultas Kedokteran Universitas Pembangunan Nasional Veteran Jakarta (FKUPNVJ) telah menyediakan PA yang bertugas membantu mahasiswa untuk menghadapi masalah. Namun, perannya terbatas dalam membantu mengatasi masalah akademik. Oleh karena itu, perlu dikembangkan intervensi dalam bentuk program dukungan mahasiswa untuk membangun ketahanan terhadap stresor dalam menghadapi tingginya prevalensi masalah akibat stres pada mahasiswa kedokteran.

Penelitian di Hongkong menyimpulkan pelatihan coping skills dan penyuluhan yang berkaitan dengan masalah kesehatan mental berguna sebagai strategi preventif. ${ }^{7} \quad$ Penelitian lainnya menunjukkan mindfulness training bermanfaat untuk mengatasi stres. Program dukungan mahasiswa dapat pula ditawarkan sebagai bagian dari kurikulum. Sejumlah intervensi termasuk counselling, cognitive behavioural training, psychotherapy, adaptive and communication skills training, dukungan sosial, relaksasi, dan latihan fisik telah terbukti mengurangi stres dan meningkatkan kualitas hidup..$^{13}$

Berkaitan dengan tingginya prevalensi masalah akibat stres pada mahasiswa kedokteran, di FKUPNVJ dirancang intervensi dalam bentuk program dukungan mahasiswa (PDM) yang bermanfaat sebagai skrining dini permasalahan psikologis dan upaya membantu mahasiswa membangun ketahanan terhadap stresor. Penelitian ini bertujuan untuk mengevaluasi pengaruh PDM terhadap stres, kecemasan, dan depresi, serta performa akademik mahasiswa.

\section{METODE}

\section{Kelaikan etik}

Persetujuan etik (ethical approval) untuk melaksanakan penelitian didapatkan dari Komisi Etik Penelitian Kesehatan Universitas Pembangunan Nasional Veteran Jakarta (Surat Nomor: B/1736/3/2019/ KEPK). Kepada calon subjek diberikan informasi dan kesempatan bertanya tentang berbagai hal berkaitan dengan penelitian mencakup tujuan, prosedur, instrumen, dan jaminan kerahasian data. Jika bersedia mengikuti penelitian, calon subjek diminta untuk menandatangani informed consent.

\section{Instrumen}

Instrumen yang dipakai adalah kuesioner Depression Anxiety Stress Scale (DASS)-42 dalam bahasa Indonesia yang terbukti valid (Cronbach $\alpha=0,94)^{14}$ dan kuesioner untuk menggambarkan sosiodemografi subjek. Tingkat masalah psikologis subjek diklasifikasi berdasarkan skor total DASS (Tabel 1). 
Tabel 1. Tingkat masalah psikologis berdasarkan skor total DASS ${ }^{14}$

\begin{tabular}{lccccc} 
& Normal & Ringan & Sedang & Berat & Sangat Berat \\
Depresi & $0-9$ & $10-13$ & $14-20$ & $21-27$ & $>28$ \\
Kecemasan & $0-7$ & $8-9$ & $10-14$ & $15-19$ & $>20$ \\
Stres & $0-14$ & $15-18$ & $19-25$ & $26-33$ & $>34$ \\
\hline
\end{tabular}

Umpan balik mahasiswa tentang pelaksanaan PDM didapatkan menggunakan instrumen kuesioner dengan lima skala Likert yang disusun oleh peneliti. Pada penelitian ini juga diambil data pencapaian akademik mahasiswa berdasarkan hasil ujian blok mencakup ujian teori berbentuk pilihan ganda (Multidisciplinary Examination/MDE) dan ujian praktikum (Objective Structured Pratical Examination/OSPE).

\section{Desain dan subjek penelitian}

Penelitian ini menggunakan one-group pretestposttest design. Kriteria inklusi subjek adalah mahasiswa semester tiga yang minimal mempunyai satu masalah psikologis baik berupa stres, kecemasan dan/atau depresi dengan tingkat ringan atau sedang berdasarkan klasifikasi skor total DASS (Tabel 1) yang diambil datanya pada saat mahasiswa tersebut semester dua serta bersedia menjadi subjek penelitian. Subjek dengan skor total DASS tergolong kategori berat atau sangat berat, mengalami krisis pada saat penelitian, dan dua kali absen dari pertemuan PDM dieksklusi dari penelitian.

\section{Populasi dan sampel}

Populasi penelitian ini adalah mahasiswa FKUPNVJ semester tiga tahun akademik 2019-2020 yang berjumlah 150 orang. Pada penelitian didapatkan 45 dari 150 mahasiswa yang memenuhi kriteria subjek penelitian.

Hasil perhitungan menggunakan power (1-】) $80 \%$ dan tingkat signifikansi (a) 5\% didapatkan besar sampel sebanyak 19 orang. Berdasarkan pertimbangan kemampuan untuk melaksanakan PDM dan mengantisipasi kemungkinan drop out, diputuskan untuk meningkatkan besar sampel menjadi 30 orang. Subjek ditentukan menggunakan teknik simple random sampling menggunakan Program
Microsoft Excel dari 45 mahasiswa yang memenuhi kriteria subjek penelitian.

\section{Program dukungan mahasiswa}

Pada penelitian ini dirancang suatu program yang disebut Program Dukungan Mahasiswa (PDM) 2019. Program tersebut diberikan kepada seluruh subjek oleh dua orang narasumber, yaitu seorang psikiater dan seorang kakak kelas subjek (peer) yang telah mengikuti pelatihan, seminar, dan mempunyai pengalaman memberikan materi terkait PDM kepada mahasiswa lain di lingkungan kampus. Pertimbangan mengikutsertakan narasumber dari peer didasarkan pada hasil penelitian di Medical University of Graz, Austria bahwa program konsultasi bagi mahasiswa yang diberikan oleh mahasiswa lain yang sudah mendapat pelatihan terbukti berhasil meningkatkan kontak konsultasi dan menurunkan masalah psikologis mahasiswa. ${ }^{15}$

PDM terdiri atas 8 pertemuan dengan durasi selama 60 menit/pertemuan yang diberikan selama 4 minggu. Kepada peserta diberikan booklet yang berisi materi setiap pertemuan PDM disertai dengan instruksi untuk berlatih secara mandiri. Program Dukungan Mahasiswa dilaksanakan menggunakan metode problem-focused coping dan emotionfocused coping. Materi PDM mencakup: pengertian resiliensi akademik, pemahaman tentang stres, kecemasan, dan depresi serta keterkaitannya dengan pikiran negatif, metode problem-focused coping (prinsip cognitive behavioural therapy, graded exposure, dan cognitive restructuring), dan emotionfocused coping (progressive muscle relaxation dan high power posture). Subjek juga diminta untuk mengerjakan tugas harian yang ditulis di dalam buku log kemudian dibahas pada setiap pertemuan. Kegiatan PDM dijabarkan pada Tabel 2. 
Tabel 2. Kegiatan program dukungan mahasiswa

Pertemuan

ke-1 Edukasi mengenai hubungan pikiran-perasaan-perilaku dan terapi kognitif perilaku; edukasi mengenai stres, kecemasan, dan depresi; pengenalan prosedur PDM

ke-2

Pengenalan progressive muscle relaxation dan mencobanya dengan mental imagery; memberikan tugas rumah berlatih progressive muscle relaxation dengan mental imagery

ke-3

Edukasi mengenai graded exposure, membuat hierarki stres dan kecemasan, memberi tugas rumah melakukan graded exposure dibantu dengan progressive muscle relaxation, mencatat efeknya terhadap pikiran, perasaan, dan perilaku

ke-4

Membahas tugas rumah melakukan graded exposure dan efeknya terhadap pikiran, perasaan dan perilaku; pengenalan cognitive restructuring; memberikan tugas rumah membuat tabel self-monitoring

ke-5

Pengenalan tentang pikiran negatif dan memberikan tugas rumah untuk mengidentifikasi dan mengelola pikiran negatif.

ke-6 Pengenalan tentang konsep dan berlatih high power posture; mengidentifikasi dan melakukan restrukturisasi distorsi kognitif

ke-7 Membahas tentang academic resilience

ke-8 Membahas tugas rumah tabel self-monitoring; menjelaskan mengenai pikiran alternatif rasional dan berlatih membuat pikiran alternatif yang rasional

\section{Prosedur penelitian}

Seluruh mahasiswa FKUPNVJ semester dua pada tahun akademik 2018-2019 yang berjumlah 150 orang diminta mengisi kuesioner DASS-42 dan sosiodemografi satu minggu sebelum ujian blok Special Sensory System (SSS) pada bulan Juni 2019. Hasil analisis data DASS didapatkan 45 mahasiswa yang memenuhi kriteria subjek penelitian. Selanjutnya dipilih secara acak 30 dari 45 orang mahasiswa tersebut untuk menjadi subjek penelitian. Data masalah psikologis dan data hasil ujian blok SSS merupakan data sebelum PDM (pretest).

Dua setengah bulan kemudian subjek yang telah menjadi mahasiswa semester tiga tahun akademik 2019-2020 mengikuti kegiatan PDM selama 4 minggu, mulai dari tanggal 21 Agustus - 20 September 2019. Pada pertemuan terakhir PDM, subjek diukur kembali tingkat masalah psikologisnya menggunakan kuesioner DASS-42 dan diminta untuk memberikan umpan balik mengenai pelaksanaan PDM. Pengukuran tingkat masalah psikologis tersebut bertepatan dengan satu minggu sebelum subjek mengikuti ujian blok HematoImunology System (HIS). Data masalah psikologis serta data hasil ujian blok HIS adalah data setelah PDM (posttest).

\section{Analisis data}

Analisis statistik dilakukan menggunakan perangkat lunak SPSS versi 17.0 (SPSS Inc.). Pada penelitian ini didapatkan distribusi data tidak normal, sehingga uji komparatif dua kelompok berpasangan yang dipakai adalah uji Wilcoxon.

\section{HASIL DAN PEMBAHASAN}

\section{Karakteristik subjek}

Sebanyak 25 (83,3\%) subjek mengikuti semua (8 pertemuan) kegiatan PDM dan 5 orang subjek $(16,7 \%)$ mengikuti 7 pertemuan. Data satu orang subjek tidak dianalisis lebih lanjut karena mempunyai skor kecemasan dan depresi yang tinggi (outlier data). Kepada subjek tersebut diberikan informasi bahwa dia dapat menghubungi peneliti untuk mendapatkan counselling/dukungan secara personal.

Berdasarkan karakteristiknya, sebagian besar subjek adalah perempuan berusia 18 tahun, berasal dari SMA di luar DKI di Pulau Jawa, masuk FK UPN melalui jalur SBMPTN, rata-rata mendapatkan uang saku harian Rp. 50.000,-, tidak tinggal bersama keluarga, dan mempunyai saudara $\leq 2$ orang (Tabel 3). 
Tabel 3. Karakteristik sosiodemografi subjek

\begin{tabular}{|c|c|c|}
\hline No. & & Karakteristik \\
\hline 1. & Jenis Kelamin & $\begin{array}{l}\text { Perempuan } 20(69 \%) \\
\text { Laki-laki } 9(31 \%)\end{array}$ \\
\hline 2. & Usia & 18 (17-19) tahun \\
\hline 3. & Asal SMA & $\begin{array}{l}\text { DKI Jakarta } 9(31 \%) \\
\text { Luar DKI, Pulau Jawa } 18 \text { (62\%) } \\
\text { Luar Jawa } 2(7 \%)\end{array}$ \\
\hline 4. & Jalur Masuk FKUPN & $\begin{array}{l}\text { SNMPTN } 10(34,5 \%) \\
\text { SBMPTN } 14(48,3 \%) \\
\text { Mandiri } 5(17,2 \%)\end{array}$ \\
\hline 5. & Uang saku harian & Rp.50.000,- \pm Rp.35.000,- \\
\hline 6. & Tempat tinggal & $\begin{array}{l}\text { Bersama keluarga } 9(31 \%) \\
\text { Tidak bersama keluarga } 20 \text { (69\%) }\end{array}$ \\
\hline 7. & Jumlah saudara & $\begin{array}{l}0 \text { orang } 3(10,3 \%) \\
1-2 \text { orang } 21(72,4 \%) \\
3-4 \text { orang } 5(17,3 \%)\end{array}$ \\
\hline
\end{tabular}

\section{Tingkat masalah psikologis subjek}

Setelah mengikuti PDM didapatkan perubahan masalah psikologis subjek pada umumnya satu atau dua tingkat berdasarkan keparahannya, misalnya dari sedang menjadi normal atau sebaliknya dari ringan menjadi sedang (Tabel 4). Namun, ada satu subjek yang mengalami perubahan tingkat masalah psikologis hingga menjadi berat dan sangat berat, sehingga dikeluarkan dari analisis data dan disarankan untuk mengikuti counselling secara personal.

Tabel 4. Tingkat masalah psikologis subjek sebelum dan sesudah PDM

Subjek Depresi Pre Depresi Post Kecemasan Pre Kecemasan Post $\quad$ Stres Pre Stres Post

$\begin{array}{lllllll}1 & \text { Ringan } & \text { Normal } & \text { Sedang } & \text { Ringan } & \text { Ringan } & \text { Normal } \\ 2 & \text { Normal } & \text { Normal } & \text { Sedang } & \text { Normal } & \text { Normal } & \text { Sedang } \\ 3 & \text { Sedang } & \text { Normal } & \text { Ringan } & \text { Sedang } & \text { Ringan } & \text { Normal } \\ 4 & \text { Normal } & \text { Normal } & \text { Ringan } & \text { Normal } & \text { Normal } & \text { Normal } \\ 5 & \text { Normal } & \text { Normal } & \text { Sedang } & \text { Sedang } & \text { Normal } & \text { Normal } \\ 6 & \text { Normal } & \text { Normal } & \text { Sedang } & \text { Berat } & \text { Sedang } & \text { Normal } \\ 7 & \text { Normal } & \text { Normal } & \text { Sedang } & \text { Sedang } & \text { Normal } & \text { Ringan } \\ 8 & \text { Normal } & \text { Normal } & \text { Sedang } & \text { Normal } & \text { Normal } & \text { Normal } \\ 9 & \text { Normal } & \text { Normal } & \text { Sedang } & \text { Normal } & \text { Ringan } & \text { Normal } \\ 10 & \text { Normal } & \text { Normal } & \text { Normal } & \text { Normal } & \text { Ringan } & \text { Normal } \\ 11 & \text { Normal } & \text { Normal } & \text { Sedang } & \text { Normal } & \text { Normal } & \text { Normal } \\ 12 & \text { Normal } & \text { Normal } & \text { Sedang } & \text { Normal } & \text { Normal } & \text { Normal } \\ 13 & \text { Ringan } & \text { Normal } & \text { Normal } & \text { Ringan } & \text { Normal } & \text { Normal } \\ 14 & \text { Normal } & \text { Normal } & \text { Ringan } & \text { Sedang } & \text { Normal } & \text { Normal } \\ 15 & \text { Normal } & \text { Normal } & \text { Sedang } & \text { Normal } & \text { Normal } & \text { Normal }\end{array}$




\begin{tabular}{lllllll}
16 & Normal & Normal & Sedang & Sedang & Normal & Normal \\
17 & Normal & Normal & Sedang & Normal & Ringan & Normal \\
18 & Sedang & Normal & Normal & Normal & Ringan & Normal \\
19 & Ringan & Normal & Sedang & Normal & Normal & Normal \\
20 & Sedang & Normal & Normal & Normal & Normal & Normal \\
21 & Sedang & Normal & Sedang & Normal & Ringan & Sedang \\
22 & Normal & Normal & Sedang & Sedang & Normal & Normal \\
23 & Normal & Normal & Sedang & Sedang & Normal & Normal \\
24 & Normal & Normal & Ringan & Normal & Sedang & Normal \\
25 & Ringan & Normal & Sedang & Ringan & Normal & Normal \\
26 & Normal & Normal & Ringan & Sedang & Normal & Ringan \\
27 & Normal & Normal & Normal & Normal & Ringan & Normal \\
28 & Sedang & Normal & Ringan & Normal & Ringan & Normal \\
29 & Ringan & Normal & Sedang & Normal & Ringan & Normal \\
30 & Normal & Ringan & Sedang & Sangat Berat & Normal & Sangat Berat \\
\hline
\end{tabular}

Berikut ini adalah hasil analisis statistik untuk ketiga masalah psikologis subjek sebelum dan setelah mengikuti PDM. Setelah mengikuti PDM, 10 orang mempunyai tingkat stres yang lebih rendah, 15 orang tetap, dan 4 orang lebih tinggi jika dibandingkan dengan tingkat stres sebelum mengikuti PDM. Hasil uji Wilcoxon menunjukkan tingkat stres subjek setelah mengikuti PDM tidak berbeda dibandingkan sebelum mengikuti PDM $(p=0,073)$, tetapi ada kecenderungan tingkat stres subjek lebih rendah setelah mengikuti PDM.

Setelah mengikuti PDM, 15 orang mempunyai tingkat kecemasan yang lebih rendah, 9 orang tetap, dan 5 orang lebih tinggi jika dibandingkan dengan tingkat kecemasan sebelum mengikuti PDM. Ada perbedaan yang signifikan pada tingkat kecemasan subjek setelah mengikuti PDM dibandingkan sebelum mengikuti PDM berdasarkan hasil uji Wilcoxon $(p=0,003)$.

Sebanyak 10 orang mempunyai tingkat depresi yang lebih rendah dan 19 orang tetap setelah mengikuti PDM. Hasil uji Wilcoxon menunjukkan ada perbedaan tingkat depresi sebelum mengikuti PDM dan setelah mengikuti PDM yang signifikan $(p=$ 0,004).

Hasil penelitian ini menunjukkan bahwa PDM dapat menurunkan masalah psikologis pada subjek satu atau dua tingkat berdasarkan tingkat keparahannya (Tabel 4). Hasil serupa didapatkan dari metaanalisis hasil sejumlah penelitian dengan subjek mahasiswa kedokteran yang menunjukkan bahwa intervensi dapat menurunkan masalah psikologis dalam jangka waktu 4-8 minggu dengan efek sedang $(r=-0,335) .{ }^{16}$ Namun, penelitian ini tidak dapat dibandingkan dengan intervensi masalah psikologis pada penelitian lain karena materi dan metode yang digunakan berbeda. Pada PDM diimplementasikan metode problem-focused coping, yaitu tindakan memodifikasi masalah yang mendasari dengan cara membuat beberapa pilihan, melihat masalah dari beberapa sudut pandang, dan melakukan sejumlah langkah untuk memecahkan masalah, serta emotion-focused coping, yaitu tindakan untuk menurunkan emosi negatif terhadap stresor ${ }^{17}$ (Tabel 2).

Salah satu metode yang digunakan dalam PDM adalah cognitive behavioural therapy (CBT) atau terapi kognitif perilaku, yaitu teknik terapi yang mengaitkan pikiran, perasaan, dan perilaku seseorang. ${ }^{18}$ Tujuan pemberian CBT adalah membuat penalaran subjek menjadi logis dengan cara melakukan hal berikut: memonitor pikiran otomatis negatif, mengenali hubungan antara pikiran, perasaan, dan perilaku, kemudian memperbaiki penalaran yang salah. Subjek yang mengikuti CBT diharapkan mempunyai 
pikiran positif. ${ }^{19}$ Hasil penelitian ini menunjukkan bahwa peserta PDM mengalami penurunan tingkat kecemasan dan depresi. Hasil ini sejalan dengan penelitian bahwa CBT berhasil membantu subjek dengan pemahaman keliru terhadap peristiwa yang tidak dialaminya yang menimbulkan emosi negatif seperti kecemasan dan depresi. Terapi kognitif perilaku bertujuan agar subjek dapat mengenali dan memperbaiki pikiran maladaptif, pikiran otomatis negatif, serta mengubah perilaku yang berkaitan dengan berbagai masalah emosional..$^{18}$

Hasil penelitian serupa menunjukkan bahwa CBT dapat meningkatkan resiliensi (kemampuan untuk bertahan dan berkembang pada saat menghadapi stresor) pada mahasiswa kedokteran. Resiliensi merupakan kunci preventif terhadap distres. ${ }^{20}$ Penelitian lain juga menunjukkan intervensi berupa program konseling dan manajemen stres berdasarkan prinsip CBT mampu menurunkan tingkat kecemasan dan depresi pada mahasiswa kedokteran secara signifikan. Cognitive behavioural therapy juga terbukti dapat mengurangi tingkat pikiran perfeksionisme maladaptif, yang menjadi ciri banyak mahasiswa kedokteran dan dapat menyebabkan kecemasan. ${ }^{21}$

Mahasiswa kedokteran seringkali harus menghadapi situasi mengalami kegagalan, ketidaklulusan, tugas-tugas yang menumpuk, dan situasi lain yang menimbulkan pikiran yang tidak rasional dan akhirnya mencetuskan kecemasan. Selain itu, perfeksionisme maladaptif juga telah terbukti berhubungan langsung dengan stres pada mahasiswa kedokteran. ${ }^{22}$ Melalui latihan cognitive restructuring diharapkan peserta PDM mampu mengontrol pikiran-pikiran tidak rasional dan menggantinya dengan pikiran yang lebih rasional. Cognitive restructuring adalah terapi yang digunakan untuk mengubah pikiran-pikiran negatif (stres dan cemas) dengan cara mengatur ulang nilai-nilai yang diyakini dengan argumentasi rasional. Cara kerjanya adalah mengidentifikasi pikiran dan mengumpulkan bukti terhadap keakuratan pikiran tersebut. Bukti tersebut akan membantu untuk mengembangkan pikiran yang lebih realistis dan meningkatkan mood sebab pikiran berdampak besar terhadap perasaan. ${ }^{23}$

Salah satu kecemasan yang dapat timbul pada mahasiswa kedokteranadalah kecemasan menghadapi ujian. Sebuah studi menunjukkan bahwa hampir 30\% mahasiswa kedokteran mengalami kecemasan yang sangat tinggi karena tidak cukupnya waktu sebelum ujian dan kurangnya latihan sebelum ujian, pikiran-pikiran irasional mengenai ujian dan ketakutan akan kegagalan. ${ }^{24}$ Pada pembahasan tugas rumah juga diindentifikasi peserta PDM mengalami kecemasan terkait akademik, yaitu pada saat harus presentasi di depan kelas dan ingin menyatakan pendapat/bertanya dalam pertemuan diskusi tutorial PBL. Melalui latihan graded exposure kecemasan tersebut diakui dapat berkurang.

Kecemasan dapat pula bermanifestasi sebagai gejala perasaan cemas maupun keluhan fisik seperti ketegangan otot. Pada pertemuan PDM, subjek dibimbing untuk melakukan progressive muscle relaxation (PMR) untuk mengurangi gejala fisik kecemasan. Progressive muscle relaxation merupakan terapi relaksasi dengan cara melakukan latihan kontraksi dan relaksasi otot secara berulang pada bagian tubuh tertentu sehingga menimbulkan perasaan rileks. Selanjutnya pada saat tubuh dan pikiran rileks, ketegangan yang membuat otot-otot berkontraksi akan diabaikan. Melalui latihan PMR, berkurangnya gejala fisik kecemasan diharapkan dapat mengurangi gejala perasaan cemas. ${ }^{25}$

Pada pertemuan sharing, salah satu peserta PDM mengungkapkan bahwa PMR terbukti dapat mengurangi gejala fisik kecemasannya pada saat belajar keterampilan klinis di skills lab. Hasil penelitian menunjukkan teknik relaksasi yang terdiri dari PMR dan autogenic training menurunkan kecemasan dan risiko kelelahan (burnout) pada mahasiswa kedokteran. ${ }^{26}$

Subjek juga diberikan prinsip high power posture untuk memodulasi hormon melalui perubahan sikap tubuh tertentu sehingga persepsi emosi negatif yang dirasakan relatif berkurang. Hasil penelitian menunjukkan high power posture dapat menyebabkan perubahan neuroendokrin dan perilaku pada subjek perempuan maupun laki-laki. High power posture terbukti dapat meningkatkan testosteron, menurunkan kortisol serta menimbulkan kekuatan dan toleransi terhadap stres. ${ }^{27}$ Menurut salah satu peserta PDM, high power posture dapat mengurangi rasa kantuknya pada saat kuliah berlangsung. 


\section{Performa akademik}

Performa akademik dalam penelitian ini dinilai berdasarkan hasil ujian teori dalam bentuk MDE dan ujian praktikum (OSPE). Namun materi ujiannya berbeda, sebelum PDM ujian blok SSS dan setelah PDM blok HIS. Hasil ujian OSPE sebelum PDM adalah 72 (38-83) dan setelah PDM menjadi 84 (52-92). Setelah mengikuti PDM, seluruh peserta (29 orang) yang mengikuti kegiatan PDM mengalami peningkatan nilai OSPE. Hasil uji Wilcoxon menunjukkan bahwa hasil ujian OSPE sebelum mengikuti PDM berbeda secara signifikan dibandingkan dengan hasil ujian OSPE setelah mengikuti PDM $(p=0,000)$.

Hasil ujian MDE sebelum PDM adalah 70,33 (3878) dan setelah PDM menjadi 70, 34 (36-76). Setelah mengikuti PDM, 12 orang mempunyai nilai MDE yang lebih rendah dan 17 orang lebih tinggi jika dibandingkan dengan nilai MDE sebelum mengikuti PDM. Hasil uji Wilcoxon menunjukkan tidak terdapat perbedaan hasil ujian MDE sebelum dan setelah mengikuti PDM yang signifikan $(\mathrm{p}=0,358)$, tetapi ada kecenderungan hasil ujian MDE subjek lebih tinggi setelah mengikuti PDM.

Hasil penelitian ini menunjukkan bahwa PDM dapat menurunkan tingkat masalah psikologis subjek sehingga berdampak baik terhadap performa akademik. Hasil penelitian ini sejalan dengan hasil penelitian di Pakistan yang menemukan adanya korelasi negatif sedang $(r=-0,478)$ antara tingkat stres dan performa akademik pada mahasiswa kedokteran. ${ }^{28}$ Penelitian lain pada mahasiswa kedokteran tahun kedua juga menunjukkan bahwa performa akademik berbanding terbalik dengan tingkat kecemasan dan depresi. ${ }^{29}$

Peningkatan performa akademik peserta PDM dapat dijelaskan berdasarkan teori bahwa stres akan mengaktifkan aksis hipotalamus-pituitary-adrenal sehingga dilepaskan hormon kortisol. Stres memiliki efek memory-modulatory. Pada hipokampus, korteks prefrontal, dan amygdala banyak terdapat reseptor kortisol. Stres akut dan tolerable dapat meningkatkan memori, sebaliknya tingkat stres yang tinggi dan kronis memiliki efek negatif. ${ }^{30}$ Sebagian besar peserta PDM mengaku telah dapat mengelola stresnya (Tabel 5), sehingga stres yang dialami menjadi tolerable.

\section{Pendapat subjek tentang PDM}

Hasil penelitian ini menunjukkan PDM dapat diterima dengan baik oleh sebagian besar subjek dan memberikan sejumlah kemampuan untuk menghadapi stres (stress coping abilities) yang telah diimplementasikan dan dirasakan manfaatnya. Namun, hasil ini tidak dapat digeneralisasi pada populasi karena besar sampel yang kecil. Umpan balik terhadap kegiatan PDM dapat dilihat pada Tabel 5.

Tabel 5. Umpan balik subjek tentang PDM

\begin{tabular}{|c|c|c|c|c|c|c|}
\hline \multirow{2}{*}{ No. } & \multirow{2}{*}{ Pernyataan } & \multicolumn{5}{|c|}{ Jumlah Subjek } \\
\hline & & STS & TS & $\mathrm{N}$ & $\mathrm{S}$ & SS \\
\hline 1. & $\begin{array}{l}\text { Saya mempraktikan/mengimplementasikan teknik-teknik mengelola } \\
\text { stres yang diberikan pada saat PDM }\end{array}$ & 0 & 1 & 4 & 22 & 3 \\
\hline 2. & $\begin{array}{l}\text { Saya lebih mudah mengontrol emosi setelah mengetahui teknik- } \\
\text { teknik yang diberikan selama PDM }\end{array}$ & 0 & 1 & 2 & 24 & 3 \\
\hline 3. & $\begin{array}{l}\text { Saya berpikir lebih rasional ketika menghadapi masalah setelah } \\
\text { mengetahui teknik-teknik yang diberikan selama PDM }\end{array}$ & 0 & 0 & 4 & 17 & 9 \\
\hline 4. & $\begin{array}{l}\text { Saya merasa terbantu ikut kegiatan PDM karena saya merasa tidak } \\
\text { sendiri menghadapi masalah }\end{array}$ & 0 & 0 & 7 & 11 & 12 \\
\hline 5. & $\begin{array}{l}\text { Narasumber PDM cukup jelas dan terbuka dalam menyampaikan } \\
\text { materi }\end{array}$ & 0 & 0 & 3 & 18 & 9 \\
\hline 6. & Ruangan untuk kegiatan PDM cukup nyaman & 0 & 0 & 13 & 15 & 2 \\
\hline
\end{tabular}


7. Waktu yang disediakan untuk kegiatan PDM kurang

8. Kegiatan PDM ini sebaiknya diadakan berkelanjutan

9. Saya merasa terbebani dalam mengikuti PDM

10. Saya membutuhkan ruang konseling dengan pakar (psikiater/ psikolog) yang disediakan oleh UPNVJ

Keterangan:

Total subjek $=30$ orang, $\mathrm{SS}=$ Sangat Setuju, $\mathrm{S}=$ Setuju, $\mathrm{N}=$ Netral, $\mathrm{TS}=$ Tidak setuju, STS $=$ Sangat Tidak Setuju.

Berdasarkan hasil umpan balik, PDM terbukti efektif karena dapat memberikan sejumlah kemampuan untuk menghadapi stres (stress coping abilities) dan dirasakan manfaatnya. Oleh karenanya, subjek menyarankan agar kegiatan PDM dapat terus ada dan berkelanjutan serta dirasakan manfaatnya oleh lebih banyak mahasiswa (Tabel 5). Mengingat keterbatasan sumber daya manusia di FKUPNVJ, ide program konseling di Medical University of Graz, Austria ${ }^{15}$ dapat ditiru, yaitu melibatkan mahasiswa (peer) yang telah dilatih agar PDM dapat berkelanjutan dan dapat membantu lebih banyak mahasiswa.

Keunggulan penelitian ini adalah menggunakan problem-focused coping dan emotion-focused coping yang diketahui berbeda efektivitasnya untuk mengatasi masalah psikologis. ${ }^{17}$ Pada penelitian lain hanya digunakan satu metode saja problem-focused coping atau emotion-focused coping, misalnya di St. Louis University, USA yang menggunakan cognitive behavioural therap $y^{21}$ atau di Friedrich-Alexander University, Jerman yang menggunakan progressive muscle relaxation. ${ }^{26}$ Keunggulan lainnya adalah penelitian ini melibatkan mahasiswa (peer) dalam memberikan intervensi sehingga subjek yang juga mahasiswa lebih "leluasa" untuk mengungkapkan atau membahas masalahnya.

Beberapa keterbatasan dalam penelitian ini adalah: 1) latihan mandiri subjek di rumah tidak dicatat, padahal banyaknya latihan mandiri merupakan faktor penting yang menentukan efektivitas program; 2) tidak ada kelompok kontrol, sehingga penurunan tingkat masalah psikologis dapat pula disebabkan oleh faktor selain intervensi PDM, misalnya penyesuaian diri yang lebih baik dari subjek terhadap lingkungan pembelajaran atau efek perhatian dari narasumber/dosen; dan 3) tidak ada pengukuran efek lanjutan dari program ini, sehingga tidak dapat diketahui bagaimana efek PDM dalam jangka waktu yang lebih panjang.

Implikasi praktis dari hasil penelitian ini adalah PDM mempunyai potensi mengatasi masalah psikologis mahasiswa dan merupakan model awal yang dapat dikembangkan oleh institusi pendidikan dokter. Program dukungan mahasiswa memiliki implikasi yang membantu mahasiswa untuk mempunyai kemampuan menghadapi stres (coping skills) yang diperlukan oleh mahasiswa dalam pendidikan dokter.

\section{KESIMPULAN}

Program Dukungan Mahasiswa di FKUPNVJ dapat menurunkan tingkat kecemasan dan depresi serta meningkatkan hasil ujian praktikum secara signifikan. Hasil tersebut menunjukkan bahwa PDM mempunyai indikasi untuk mengatasi masalah psikologis mahasiswa yang berdampak terhadap peningkatan performa akademik. Agar didapatkan data yang lebih komprehensif perlu dilakukan penelitian dengan metode campuran (mixed method research), menggunakan kelompok kontrol, dan menambah besar sampel.

\section{SARAN}

Mengingat pentingnya ketahanan terhadap stresor pada mahasiswa kedokteran, disarankan kepada institusi pendidikan dokter untuk merancang dan mengembangkan program dukungan mahasiswa secara berkesinambungan.

\section{UCAPAN TERIMA KASIH}

Terima kasih kepada Riduan Rijky, SKed. atas kesediaannya berbagi pengalaman kepada adik 
kelasnya sebagai narasumber PDM dan membantu pelaksanaan penelitian ini. Terima kasih juga atas kesediaan dan kesungguhan mahasiswa FKUPNVJ untuk menjadi peserta PDM dan memberikan umpan balik terkait program. Penelitian ini dapat terlaksana berkat dukungan dana dan moril dari LPPM UPNVJ, oleh karenanya peneliti berterima kasih kepada Ketua beserta seluruh staf LPPM UPNVJ.

\section{DEKLARASI KEPENTINGAN}

Para penulis mendeklarasikan bahwa tidak terdapat konflik kepentingan apapun terkait studi pada naskah ini.

\section{KONTRIBUSI PENULIS}

Nurfitri Bustamam - mendesain penelitian, menganalisis dan menginterpretasi data, membuat draft dan merevisi naskah berdasarkan catatan redaksi

Ria Maria Theresa - mendesain penelitian dan menginterpretasi data

Sri Wahyuningsih - mengumpulkan data dan membantu merevisi naskah

\section{DAFTAR PUSTAKA}

1. Dyrbye LN, Thomas MS, Shanafelt TD. Medical student distress: causes, consequences, and proposed solutions. Mayo Clinic Proc. 2005;80(12):1613-22.

2. Benbassat J, Baumal R, Chan S, Nirel N. Sources of distress during medical training and clinical practice: suggestions for reducing their impact. Med Teach. 2011;33:486-90.

3. Mavor KI, McNeill KG, Anderson K, Kerr A, Platow MJ. Beyond prevalence to process: the role of self and identity in medical student wellbeing. Med Educ. 2014;48:351-60.

4. Saipanish R. Stress among medical students in a Thai medical school. Med Teach. 2003; 25(5):502-6.

5. Hope V, Henderson M. Medical student depression, anxiety and distress outside North America: a systematic review. Med Educ. 2014;48:963-79.
6. Dahlin M, Joneborg N, Runeson B. Stress and depression among medical students: a crosssectional study. Med Educ. 2005;39:594-604.

7. Wong JGWS, Path NG, Beh SL, Cheung EPT, Wong V, Chan LC, Mak FL. Cultivating psychological well-being in Hong Kong's future doctors. Med Teach. 2005;27(8):715-9.

8. Hardisman, Pertiwi D. Gambaran distress pada mahasiswa preklinik tahun ketiga fakultas kedokteran. JPKI 2014;3(3):145-53.

9. Bakhriansyah M. Korelasi antara lama studi dan tingkat kecemasan mahasiswa. JPKI 2012; 1(2):54-8.

10. Park KH, Kim D-h, Kim SK, Yi YH, Jeong JH, Chae J, Hwang J, Roh H. The relationships between empathy, stress and social support among medical students. Int J Med Educ. 2015;6:103-8

11. Sandars J, Patel R, Steele H, Mcareavey M. Developmental student support in undergraduate medical education: AMEE Guide No. 92. Med Teach. 2014;36:1015-26.

12. Konsil Kedokteran Indonesia. Standar Pendidikan Profesi Dokter Indonesia. Jakarta: KKI; 2012.

13. Ishak W, Nikravesh R, Lederer S, Perry R, Ogunyemi D. Bernstein C. Burnout in medical students: a systematic review. Clin Teach. 2013;10:242-5.

14. Damanik ED. Depression anxiety stress scales. Psychology Foundation of Australia. 2014 [cited October 2015]. Available from: http://www2. psy.unsw. edu.au/dass/Indonesian/Damanik. htm

15. Vadja C. "Peer2Peer" - A university program for knowledge transfer and consultation in dealing with psychosocial crises in med-school and medical career. GMS J Med Educ. 2016;33(4):111.

16. Yusoff M. Interventions on medical students' psychological health: a meta-analysis. J Taibah Univ Med Sci. 2014;9:1-13.

17. Baker JP, Berenbaum H. Emotional approach and problem focused coping: a comparison of 
potentially adaptive strategies. Cognition and Emotion 2007;21(1):95-118.

18. Nevid JS, Rathus SA, Greene BS. Abnormal psychology in a changing world. $9^{\text {th }}$ ed. New York: Pearson; 2014.

19. Townsend MC. Psychiatric mental health nursing: concepts of care in evidence based practice. $6^{\text {th }}$ ed. Philadelphia: F.A. Davis Company; 2009.

20. Sood A, Prasad K, Schroeder D, Varkey P. Stress management and resilience training among Department of Medicine faculty: a pilot randomized clinical trial. J Gen Intern Med. 2011;26:858-61.

21. Chand SP, Chibnall JT, Slavin SJ. Cognitive behavioural therapy for maladaptive perctionism in medical students: a preliminary investigation. Acad Psychiatry 2018;42:58-61.

22. Dyrbye LN, Thomas MR, Shanafelt TD. Systematic review of depression, anxiety, and other indicators of psychological distress among U.S. and Canadian medical students. Acad Med. 2006;81:354-73.

23. Cognitive Restructuring. [Cited: 15 September 2019]. Available from: https://www.talkplus.org. uk/ downloads/ Cognitive\%20Restructuring. pdf

24. Guraya SY, Guraya SS, Habib F, AlQuiliti KW, Khoshhal KI. Medical students' perception of test anxiety triggered by different assessment modalities. Med Teach. 2018;40:49-55.

25. Conrad A, Roth TW. Muscle relaxation therapy for anxiety disorders: it works but how? J Anxiety Disord. 2007;21:243-64.

26. Wild K, Scholz M, Ropohl A, Bra"uer L, Paulsen F, et al. Strategies against burnout and anxiety in medical education: implementation and evaluation of a new course on relaxation techniques (relacs) for medical students. PloS ONE 2014;9(12):e114967.

27. Carney DR, Cuddy AJ, Yap AJ. Power posing: brief nonverbal displays affect neuroendocrine levels and risk tolerance. Psychol Sci. 2010;21:1363-8.

28. Sohail N. Stress and academic performance among medical students. J Coll Physicians Surg Pak. 2013;23(1):67-71.

29. Mihailescu AI, Diaconescu LV, Ciobanu AM, Donisan T. Mihailescu C. The impact of anxiety and depression on academic performance in undergraduate medical students. The $24^{\text {th }}$ European Congress of Psychiatry/European Psychiatry; 2016.

30. Lindau $\mathrm{M}$, Almkvist $\mathrm{O}$, Mohammed $\mathrm{AH}$. Chapter 18: Effects of stress on learning and memory. In: Fink G, editor. Stress: concepts, cognition, emotion, and behavior: handbook of stress series volume 1. Academic Press; 2016. p153-60. 